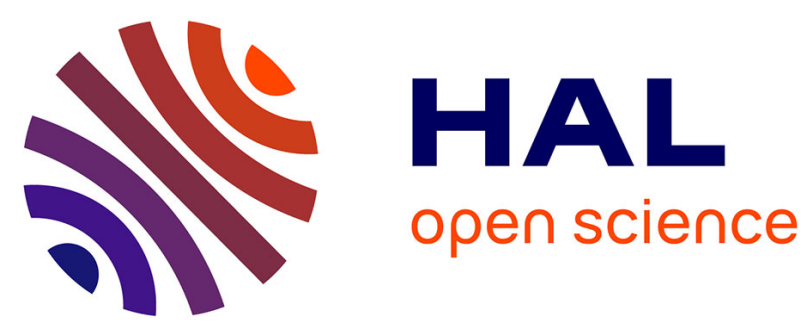

\title{
Magnetic birefringence in mixtures of a nematic aromatic polyester and PAA
}

J.M. Gilli, G. Maret, P. Maissa, A. ten Bosch, P. Sixou, A. Blumstein

\section{To cite this version:}

J.M. Gilli, G. Maret, P. Maissa, A. ten Bosch, P. Sixou, et al.. Magnetic birefringence in mixtures of a nematic aromatic polyester and PAA. Journal de Physique Lettres, 1985, 46 (7), pp.329-334. 10.1051/jphyslet:01985004607032900 . jpa-00232519

\section{HAL Id: jpa-00232519 https://hal.science/jpa-00232519}

Submitted on 1 Jan 1985

HAL is a multi-disciplinary open access archive for the deposit and dissemination of scientific research documents, whether they are published or not. The documents may come from teaching and research institutions in France or abroad, or from public or private research centers.
L'archive ouverte pluridisciplinaire HAL, est destinée au dépôt et à la diffusion de documents scientifiques de niveau recherche, publiés ou non, émanant des établissements d'enseignement et de recherche français ou étrangers, des laboratoires publics ou privés. 
Classification

Physics Abstracts

$61.30 \mathrm{E}-78.20 \mathrm{~F}$

\title{
Magnetic birefringence in mixtures of a nematic aromatic polyester and PAA
}

\author{
J. M. Gilli, G. Maret (*), P. Maissa, A. Ten Bosch, P. Sixou and A. Blumstein (**) \\ Laboratoire de Physique de la Matière Condensée $\left({ }^{+}\right)$, Parc Valrose, 06034 Nice Cedex, France
}

(Reçu le 5 juin 1984, révisé le 15 janvier 1985, accepté le ler février 1985)

\begin{abstract}
Résumé. - On a examiné la biréfringence magnétique dans un mélange d'un cristal liquide de petites molécules (PAA) et d'un polymère nématique. La constante de Cotton-Mouton $(C M)$ suit une loi $(C M)^{-1}=\alpha\left(T-T_{*}\right)$ pour toute la gamme de concentration. $\alpha$ ainsi que $T_{*}$ croissent avec la concentration de polymère nématique. On compare avec une théorie de champ moyen d'un mélange de polymère à longueur de persistance et d'un cristal liquide rigide.
\end{abstract}

Abstract. - The magnetic birefringence was measured in a mixture of a small molecule liquid crystal (PAA) and a nematic polymer. The Cotton-Mouton constant $C M$ follows a law $(C M)^{-1}=\alpha\left(T-T_{*}\right)$ in the entire concentration range. Both the slope $\alpha$ and the super cooling temperature $T_{*}$ increase with increasing polymer concentration. Comparison is made with a meanfield theory of a mixture of a worm-like polymer and a rigid rod liquid crystal.

\section{Introduction.}

Pretransitional effects above the order-disorder transition temperature $T_{\mathrm{c}}$ of nematic liquid crystals can be explored with the help of magnetic field induced birefringence [1]. The measurements in small molecule liquid crystals are extensive [2-5] and have raised the question of the range of validity of a classical mean field description [6-8] in the vicinity of $T_{\mathrm{c}}$ [9]. Recently measurements were performed on polymeric liquid crystal melts $[10,11 \mathrm{a}]$. In the aromatic polyester (DDA-9), the temperature dependence of the Cotton-Mouton constant $C M$ was measured as a function of the degree of polymerization. These experiments demonstrated a strictly quadratic magnetic field dependence of the birefringence, a linear variation of $C M^{-1}$ with $T$ and an extrapolated temperature $T_{*}\left(1 / C M \rightarrow 0, T \rightarrow T_{*}\right)$ with $T_{\mathrm{c}}-T_{*}$ much larger than those found in small molecule liquid crystals, such as PAA with a similar mesogenic group. In this paper, we report results on mixtures of the same nematic polymer DDA-9, with the small molecule liquid crystal PAA. This system is miscible over the whole range of concentration and allows a conti-

$\left(^{*}\right)$ Hochfeld - Magnet Labor, Max Planck Institut für Festkörperforschung, F-38042 Grenoble, France.

$\left({ }^{* *}\right)$ Dept. of Chemistry, University of Lowell, Lowell, Mass. 01854, U.S.A.

$\left(^{+}\right)$Laboratoire associé au CNRS, $n^{\circ} 190$. 
nuous study to be made of those properties which may arise from the polymeric nature of one of the components.

\section{Experimental.}

The polyester DDA-9 has the chemical formula :<smiles>Cc1cc(OC(C)(C)C)ccc1N=N[14C](=O)Nc1ccc(OC(=O)CCCCCCCC(=O)OC(C)(C)C)cc1C</smiles>

$n$ being the degree of polymerization.

The molecular weight was determined to be $\sim 4000$ and the polydispersity $\leqslant 2$.

The PAA was of commercial origin and was purified by sublimation in vacuum. The mixtures of PAA and DDA-9 were prepared at room temperature (below the melting point). Homogenization was obtained by keeping the samples several hours inside the Hellma cells $(0.1 \mathrm{~cm}$ thickness) used for the birefringence measurements at a temperature some $20^{\circ}$ above $T_{\mathrm{c}}$, i.e. in the isotropic melt.

The measurements of magnetic birefringence $\Delta n=\left(n_{\|}-n_{\perp}\right)$ were performed at the high field facility of the Max-Planck Institute at Grenoble. A detailed description of the apparatus has been given elsewhere [12]. The molecular orientation as probed by $\Delta n$ was in continuous thermal equilibrium during each sweep of magnetic field $(0 \leqslant H \leqslant 12 \mathrm{~T})$ and a quadratic dependence of the birefringence in the magnetic field was observed, $\Delta n=C M . \lambda . H^{2}(\lambda=632.8 \mathrm{~nm})$. This allowed calculation of the Cotton-Mouton constant $C M$. The optical transmission measu-

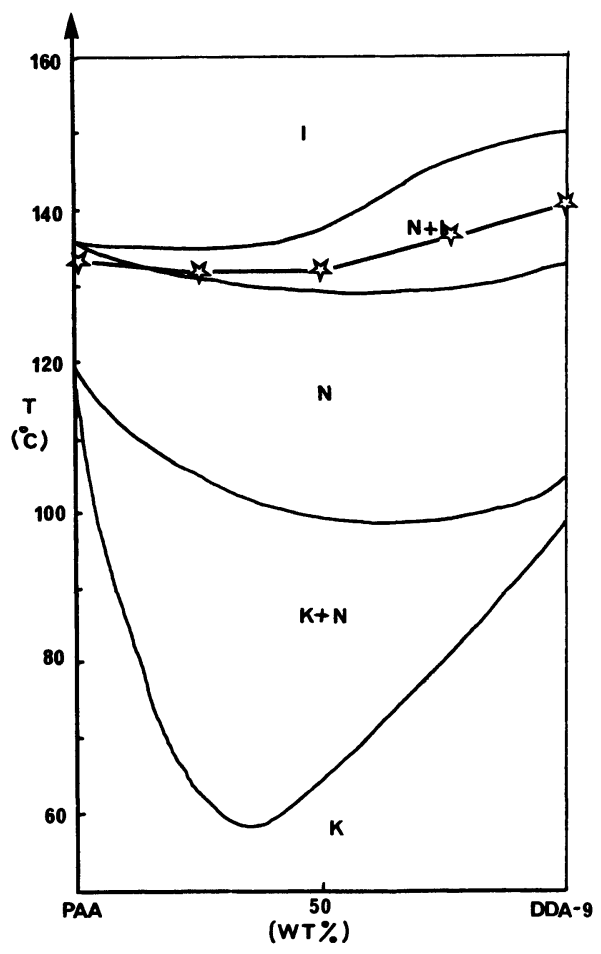

Fig. 1. - Experimental phase diagram for the mixture PAA + DDA-9 $\left(M_{n} \sim 4000\right)$ from [13] the stars show the diagram obtained from birefringence on cooling. 
rements were realized within the same apparatus. The transition temperature $T_{\mathrm{c}}$ was determined from the sharp drop in the birefringence caused by the appearance of the anisotropic phase on cooling (cooling rate $0.5^{\circ} \mathrm{C} / \mathrm{min}$ ). The phase diagram DDA-9-PAA obtained with this method is given in figure 1, superimposed on the phase diagram obtained by optical microscopy [13]. The temperature obtained for the $\mathrm{N}+\mathrm{I} \rightarrow \mathrm{I}$ transition differs in the two methods due to a hysteresis effect. In the polarizing microscope, the sample is heated and not cooled as in the birefringence experiment.

A linear variation of $C M^{-1}$ with temperature is observed at temperatures sufficiently far above the temperature at which the first anisotropic droplets appear. We can thus determine by extrapolation the temperature $T_{*}$ (at which $C M$ would diverge). In pure PAA, we find $T_{\mathrm{c}}-T_{*} \sim 4^{\circ} \mathrm{C}$, whereas in pure DDA-9 $T_{\mathrm{c}}-T_{*} \sim 30^{\circ} \mathrm{C}[11,11 \mathrm{a}]$; in the polymer the transition appears more " strongly » first order. The behaviour intermediate between these two types of liquid crystals can be studied in the mixture.

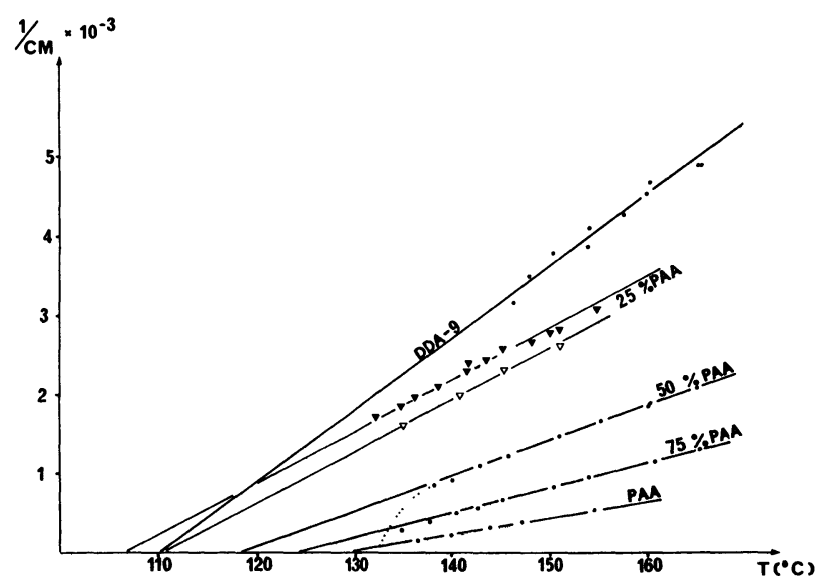

Fig. 2. - Inverse Cotton-Mouton constant $1 / C M$ as a function of temperature $T$ for several concentrations of PAA. In the case of $25 \%$ PAA the two curves show a degradation effect occurring with time : the full triangles correspond to a sample maintained longer at isotropic temperature.

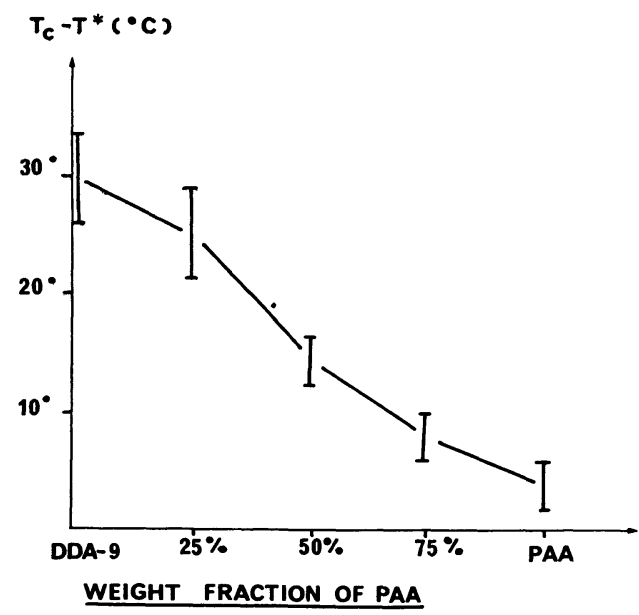

Fig. 3. $-\left(T_{\mathrm{c}}-T_{*}\right)$ as a function of concentration of PAA. 


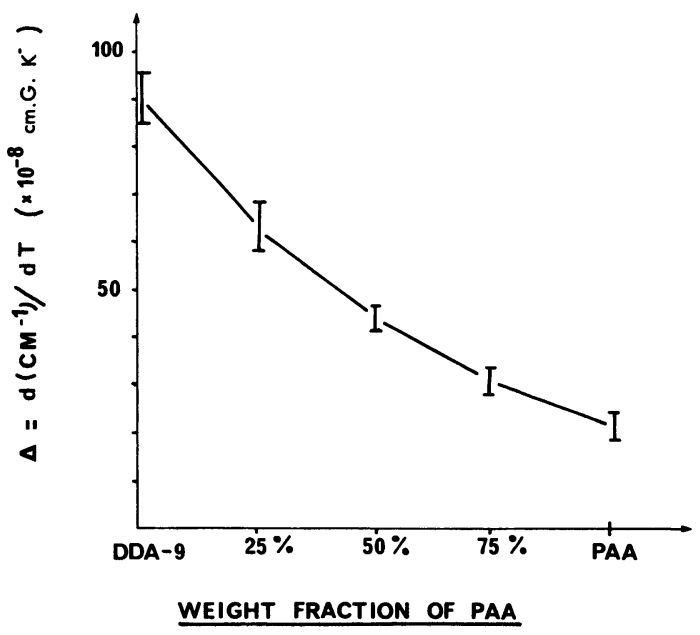

Fig. 4. - Slope of the curve of $1 / C M$ versus $T$ (given in Fig. 2) as a function of concentration of PAA.

In all cases examined, the law $C M^{-1}=\alpha\left(T-T_{*}\right)$ is conserved as shown in figure 2 . The values of $\left(T_{c}-T_{*}\right)$ vary continuously between the polymer and PAA (Fig. 3). The slope $\alpha=\mathrm{d} C M^{-1} / \mathrm{d} T$ of the linear temperature plot of figure 2 decreases with increasing $C$ as shown in figure 4.

For the mixture with $75 \%$ of DDA-9, the precision and reproducibility on the $T_{\mathrm{c}}, T_{*}$ is bad probably due to the high viscosity. Homogeneity in the melt can only be obtained by waiting many hours at the isotropic temperature and this leads to an important degradation process on DDA-9 : figure 2 shows two different results depending on the waiting time at high temperature and a decrease of $T_{\mathrm{c}}$ and $T_{*}$ with time. In spite of this, the reproducibility of the measurement of $T_{\mathrm{c}}-T_{*}$ and of the slope of $1 / C M$ versus $T$ seem to be acceptable. The cross bars on figures 3 and 4 show the better precision obtained in the high PAA concentration mixtures.

\section{Discussion.}

Measurements of $C M$ have been used to test the validity of the Landau-de Gennes theory near $T_{\mathrm{c}}$ and to determine the parameters $A, T_{*}$ of the free energy expansion in the homogeneous isotropic phase :

$$
F(S)=A\left(T-T_{*}\right) S^{2}-\frac{1}{3} \Delta \chi H^{2} S+\cdots
$$

to lowest order in $T, S, H$.

$\Delta \chi$ is the anisotropy of magnetic susceptibility. From $\partial F(S) / \partial S=0$ the order parameter $S=\frac{\Delta \chi H^{2}}{6 A\left(T-T_{*}\right)}$ and the $C M$ constant $C M=\frac{\Delta n_{0} . S}{\lambda H^{2}}$ can be calculated. Here, $\Delta n_{0}$ is the refractive index of the fully oriented nematic. From the slope $\alpha$ of $C M(T)$ and latent heat measurements $\Delta \tilde{H}=\frac{A}{2} \cdot S_{\mathrm{c}}^{2} \cdot T_{\mathrm{c}}$ the critical order parameter $S_{\mathrm{c}}$ at $T_{\mathrm{c}}$ is deduced. In small molecule liquid crystals (SMLC), good agreement with other order parameter measurements is obtained. In polymer liquid crystals (PLC), a conformational entropy latent heat contribution is present [14] which must be considered when extracting $S_{\mathrm{c}}$ from $\Delta \tilde{H}$. 
So far, no measurements on the latent heat $\Delta \tilde{H}$ have been made in the DDA-9/PAA mixture. In SMLC, the slope of the experimental $C M^{-1}$ curves deviate from $\alpha$ at about $1{ }^{\circ} \mathrm{C}$ above $T_{\mathrm{c}}$ [3]. This has been interpreted as the onset of critical fluctuations in the order parameter near the transition temperature. A theoretical investigation including fluctuations [9] shows that $C M^{-1}$ may increase more rapidly than $\left(T-T_{*}\right)$ close to $T_{\mathrm{c}}$. Care must therefore be taken in the extrapolation of the experimental data near $T_{\mathrm{c}}$ to determine $T_{*}$. In PLC, these fluctuations may be strongly damped due to higher values of the elastic constants [15]. Indeed, mean field calculations of $T_{*}$ of PLC, including orientation dependent interactions only [16], are in better agreement with the experimental values than in the case of SMLC. In the mixture $A_{c-1} B_{c}$ of a PLC (called A) and a SMLC (called B) an average $C M$ constant is measured. This is directly related to the weight averaged order parameter $\bar{S}=(c-1) S_{\mathrm{A}}+(c) S_{\mathrm{B}}$ (in the case of equal refractive index). Using the elastic worm-like chain model, $S$ has been calculated using the method described in [17] and including the magnetic field contribution to the molecular potential :

$$
V_{\mathrm{e}}(s)=-\frac{1}{3} \Delta \chi H^{2} \cdot\left(\frac{3}{2} \cos ^{2} \theta_{\mathrm{A}}(s)-1 / 2\right),
$$

$\theta_{\mathrm{A}}$ being the angle between the nematic director and the tangent, at position $s$ of the worm-like polymer (of persistence length $q$ ). The theoretical results for the order parameter are given in

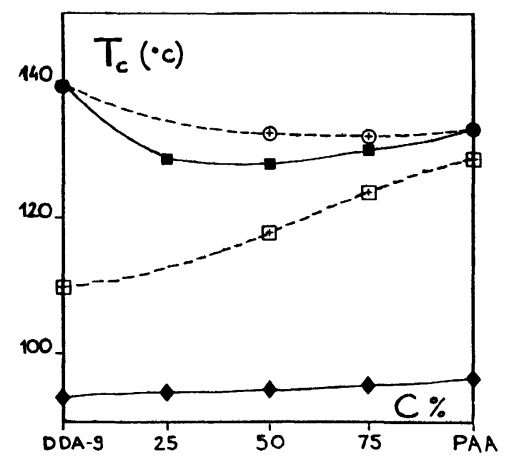

(a)
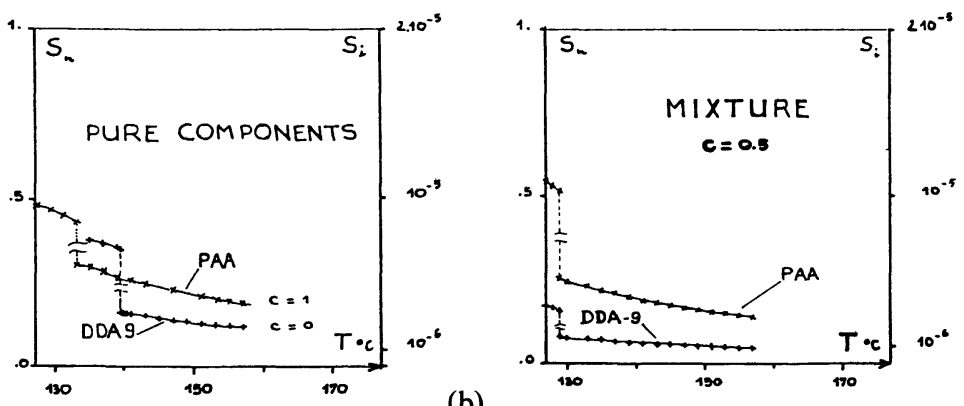

(b)

Fig. 5. - (a) Comparison between the theoretical $(--)$ and experimental $(--\oplus--)$ phase diagram for the mixture of a rigid rod liquid crystal (PAA) and a liquid crystalline polymer of persistence length one monomer (DDA-9). Theoretical $(--)$ and experimental $(-\boxplus-)$ values corresponding to the $T_{*}$ temperature as a function of PAA concentration. (b) Order parameters in the nematic $\left(S_{\mathrm{N}}\right)$ and the isotropic $\left(S_{\mathrm{I}}\right)$ phase as a function of temperature for both pure components and the mixture $(C=0.5) .(+)$ for the DDA-9; $(\times)$ for the PAA. $\left(\Delta \chi=10^{-28} \mathrm{erg} \mathrm{G}^{-2}\right)$. 
figure 5b. In the isotropic phase $\bar{S} \sim 10^{-6}$ leading to the correct order of magnitude for $C M$ (example DDA-9: $c=100 \%, S=8 \times 10^{-6}, T=140^{\circ} \mathrm{C}, C M^{-1}=4 \times 10^{3} \mathrm{~cm} \mathrm{~T} \mathrm{~T}^{2}$ ). However, the slope of $\bar{S}^{-1}(T)$ increases with increasing $C$. This is in contradiction to experiment and might be related to the fact that the calculated $S_{\mathrm{A}}$ value at $T_{\mathrm{c}}$ is smaller than $S_{\mathrm{p}}$ at $T_{\mathrm{c}}$ rather than larger as found experimentally [11] and, as proposed recently by P. G. de Gennes [18], the pretransitional increase of the orientational correlation length could imply a chain stiffening which would suggest $S_{\mathrm{A}} \geqslant S_{\mathrm{B}}$ in qualitative agreement with the experiments. On the other hand, even exact meanfield calculations do not appear to describe the SMLC birefringence accurately $[6,7]$ and the calculated temperature $T_{*}$ in the liquid crystal rich phase is too large [19]. The pseudo-transition temperature of the mixture [17] approximates the experimental curves except for large biphasic zones (polydispersity) in the polymer rich mixtures (Fig. 5).

Finally, uncertainties in parameters of the polymer system such as degree of polymerization, persistence length, anisotropy of susceptibility, refractive index and transition temperature make more quantitative comparison difficult at present. Better determination of the polymer characteristics and more studies of pretransitional phenomena (light scattering) are needed.

\section{References}

[1] Priestley, E. B., Sheng, R., Wojtowicz, P., Introduction to liquid crystals, 1974.

[2] Rosenblatt, C., Phys. Rev. A 27 (1983) 1234.

[3] Malraison, B. and Poggi, Y., Filipini, J. C., Solid State Commun. 31 (1979) 843.

[4] Stinson, T. W. and Litster, J. D., Phys. Rev. Lett. 25 (1970) 503.

[5] FilipPini, J. C. and Poggi, Y., J. Physique Lett. 37 (1976) L-17.

[6] Palfy-Muhoray, P. and Dunmur, D., Phys. Lett. A 91 (1982) 121.

[7] Palfy-Muhoray, P. and Dunmur, D., Mol. Cryst. Liq. Cryst. 97 (1983) 337.

[8] Shen, J., Chai-Wei Woo, Phys. Rev. A 24 (1981) 494.

[9] Chung-Peng, Fan and StePhen, M., Phys. Rev. Lett. 25 (1970) 500.

[10] Maret, G., Volino, F., Blumstein, R. B., Martins, A. F., Blumstein, A., Proc. 27th Int. Symp. Macromolecules (1981) Strasbourg.

[11] Maret, G., ACS Symposium, Washington (1983), Polymer Preprints 24 (2) (1983) 249.

[11a] MARET, G., in preparation.

[12] Maret, G. and Weill, G., Biopolymers 22 (1983) 2727.

[13] Blumstein, A., Schmidt, H. W., Thomas, O., Kharas, G. B., Blumstein and Ringsdorf, Mol. Cryst. Liq. Cryst. 92 (1984) 271.

[14] Ten Bosch, A., Maissa, P., Sixou, P., J. Physique Lett. 44 (1983) L-1105.

[15] Ciferri, A., Krigbaum, W. R., Meyer, R., Polymer Liquid Crystals, 1982.

[16] Ten Bosch, A., Maissa, P., Sixou, P., Physica A (to be submitted).

[17] Ten Bosch, A., Maissa, P., Sixou, P., J. Chem. Phys. 79 (1983) 3462.

[18] De Gennes, P. G., submitted to Mol. Cryst. Liq. Cryst. (Lett.).

[19] Senbetu, L., Chia-Wei Woo, Mol. Cryst. Liq. Cryst. Lett. 84(1982) 101. 